\title{
Representações das emoções do trabalho docente em uma perspectiva histórica'
}

\author{
Marina Mendes da Costa ${ }^{2}$ \\ ORCID: 0000-0002-1400-5457 \\ Rosario Silvana Genta Lugli ${ }^{3}$ \\ ORCID: 0000-0001-7893-8646
}

\section{Resumo}

Este artigo apresenta os resultados de um estudo cujo objetivo foi identificar as representações, compreendidas na acepção de Chartier, a respeito das dimensões emocionais do trabalho dos professores primários em São Paulo, entre as décadas de 1950 e 1970. Utilizaram-se, para tanto, romances autobiográficos de professoras que exerceram o magistério no período, as revistas produzidas pelo Centro do Professorado Paulista - CPP, bem como as produções da Revista Brasileira de Estudos Pedagógicos - RBEP, como forma de comparar as representações acerca das dimensões emocionais do trabalho docente produzidas pelos próprios professores e as representações produzidas pelos pesquisadores em educação, divulgadas pela RBEP. As emoções são defınidas, a partir de Estrela e Damásio, como um sistema dinâmico que proporciona o lidar com o desconhecido e tomadas de consciência, além do julgamento constante (inconsciente e consciente) das ameaças e das oportunidades do cotidiano. As dimensões emocionais do trabalho docente são entendidas como um conjunto de emoções resultantes das interações dos professores no exercício da docência: a relação com os alunos, família, os demais profissionais do ambiente escolar, bem como as emoções decorrentes das condições de trabalho e as mudanças na estrutura educacional. A análise das fontes permitiu identificar em que medida as representações sobre as emoções no trabalho docente estavam relacionadas com a produção do discurso acerca da formação e da prática do professor primário, bem como com a constituição e divulgação da representação do professor primário pelo CPP.

\section{Palavras-chave}

História da profissão docente - Emoção e trabalho docente - Representações sociais.

\footnotetext{
1- 0 presente trabalho foi realizado com apoio da Coordenação de Aperfeiçoamento de Pessoal de Nível Superior - Brasil (CAPES) - Código de Financiamento 001.

2- Universidade de São Paulo, São Paulo, SP, Brasil. Contato: marinamcost@gmail.com.

3- Universidade Federal de São Paulo, São Paulo, SP, Brasil. Contato: genta.lugli@unifesp.br.
}

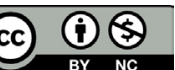




\section{Representations of the emotions of teaching in a historical perspective}

\section{Abstract}

This paper presents the results of a research whose objective was to identify the representations, according to Chartier's use of the concept, about the emotional dimensions of the work by elementary school teachers in São Paulo, between the 1950s and 1970s. For this purpose, autobiographical novels by teachers of the period, magazines produced by the São Paulo Teachers Center - CPP, as well as the productions of the Brazilian Journal of Pedagogical Studies - RBEP, were used as a way to compare the representations about the emotional dimensions of teaching produced by the very teachers and the representations produced by education researchers, published by RBEP. Emotions are defined, drawing from Estrela and Damásio, as a dynamic system that makes possible to deal with the unknown and awareness, as well as the constant (unconscious and conscious) judgment of everyday threats and opportunities. The emotional dimensions of teaching are understood as a set of emotions that emerge with the teachers' interactions in their everyday activities: the relationship with students, family and other professionals in the school environment, as well as the emotions arising from working conditions and changes in the educational structure. The analysis of the sources allowed us to identify to what extent the representations about emotions in teaching were related to the production of a discourse about the education and the practice of the elementary teacher, as well as to the constitution and dissemination of the representation of elementary school teachers by CPP.

\section{Keywords}

History of the teaching profession - Emotions and teaching - Social representations.

0 trabalho docente tem uma dimensão emocional, presente, entre outros aspectos, nas tarefas de regulação disciplinar da classe, na sensibilidade que se espera dos professores para compreender quando um aluno precisa de atenção especial. Hargreaves (1998, p. 835) afirma que "as emoções estão no coração do ensino", no entanto, são poucos e recentes os trabalhos que buscam investigar o lugar das emoções na profissão docente. Essa dimensão emocional regula as interações na sala de aula e permite colocar em primeiro plano alguns aspectos do trabalho quando se constroem as representações a seu respeito. Ao olharmos para as representações acerca da docência no século XX, observam-se mudanças muito significativas na imagem social dos professores, com referência ao sacerdócio, aos deveres de funcionário público e, finalmente, ao trabalhador em educação.

Sabendo disso, este texto pretende contribuir para a compreensão de um processo histórico que progressivamente constrói representações das emoções dos professores em sala de aula como fruto de alguns problemas no ensino, como desajustes emocionais. Em 
contrapartida, temos no mesmo processo os usos sociais das representações das dimensões emocionais do trabalho docente pelas professoras primárias, para dar visibilidade ao seu trabalho. Para analisar essa temática, selecionamos fontes que pudessem mostrar o funcionamento dessas representações em diferentes locais do campo educacional (BOURDIEU, 2004). Foram analisados os artigos da Revista Brasileira de Estudos Pedagógicos (RBEP), do Instituto Nacional de Estudos Pedagógicos (INEP), como forma de analisar as representações de um meio de divulgação legítimo da produção científica em educação do período. Para poder estudar, em contrapartida, as representações produzidas pelas professoras primárias, utilizamos os artigos produzidos pela revista da associação mais antiga ainda em funcionamento de São Paulo, a Revista do Professor do CPP (publicada entre 1934 e 1964) e as representações presentes em romances memorialísticos de professoras primárias paulistas.

0 período analisado compreende as décadas de 1950 a 1970 e foi um momento de importantes reformas iniciadas a partir de acordos internacionais engendrados pela UNESCO como forma de elevar os índices de alfabetização no país. Desta forma, temos ações que começaram a investir na pesquisa em educação, como é o caso da inauguração dos Centros Regionais de Pesquisas Educacionais, em 1955, que tinham uma dupla finalidade: contribuir para compreensão da escola brasileira a partir da pesquisa científica e promover ações para formação continuada de professores e administradores educacionais. Temos ainda nesse período a promulgação do Acordo número 1 de Educação pela UNESCO, em 1958, que promoveu uma série de medidas com o objetivo de combater o analfabetismo e desenvolver a educação nos países subdesenvolvidos. Ora, este movimento fez com que se intensificasse o número de propostas e artigos a respeito da formação de professores e, mais especificamente, acerca da formação continuada dos professores em exercício.

A respeito da formação dos professores primários, temos um cenário de discussão acerca da necessidade de modificação das práticas escolares, para incorporação de novas metodologias derivadas dos novos estudos em educação. Portanto, temos nas fontes, especialmente na RBEP, a representação de um professor primário que precisa se atualizar para a modernização da escola. Essa necessidade de atualização foi justificada, no caso dos artigos da RBEP, pela inadequação do modo de trabalho dos professores e foi compreendida de modo ambivalente pelos professores primários, tanto em termos de adesão aos novos referenciais como de defesa dos valores tradicionais, no caso da Revista do Professor e dos romances memorialísticos das professoras primárias.

Pode-se dizer que estava em jogo a modificação do habitus dos professores. Ao desenvolver o conceito de habitus, Bourdieu procurava descrever "[...] a história encarnada nos corpos sob a forma de disposições duráveis" (BOURDIEU, 2001, p. 41), isto é, um conjunto de estruturas objetivas internalizadas que possibilitam a interação do agente com o mundo social, orientando suas práticas e a construção de suas representações:

0 habitus é ao mesmo tempo um sistema de esquemas de produção de práticas e um sistema de esquemas de percepção e apreciação das práticas. E, nos dois casos, suas operações exprimem a posição social em que foi construído. Em consequência o habitus produz práticas e representações que estão disponíveis para a classificação que são objetivamente diferenciados. (BOURDIEU, 1990, p. 158). 
Habitus é, portanto, uma concepção de mundo enraizada culturalmente: valores, formas de perceber o mundo, formas de organizar, de interagir que são culturalmente herdadas, portanto, são comuns a todo um grupo, mas ao mesmo tempo têm uma expressão individual que é dada ao agente em sua relação com o cotidiano: "o habitus é essa espécie de senso prático do que se deve fazer em cada situação” (BOURDIEU, 1996, p. 42). Desta maneira, ao falar de habitus professoral, tratamos de um modo de ser dos professores, das estruturas de ação de percepção próprias desse grupo. Esse contexto de mudanças na profissão docente revela-se um marco para a discussão de questões relativas à representação social do professor primário, registradas em congressos de educação e em publicações dos Centros Regionais de Pesquisas Educacionais - CRPEs e da RBEP, em todo o país (FERREIRA, 2008; GANDINI, 1990).

A Revista Brasileira de Estudos Pedagógicos do INEP, editada desde 1944, torna-se uma das principais disseminadoras de um conhecimento especializado sobre educação reproduzindo em suas publicações, relatórios e informativos sobre eventos educacionais que aconteceram no Brasil e no exterior, pesquisas realizadas nas universidades do país e pelos CRPEs que, no momento estudado, tiveram forte atuação na produção e divulgação de pesquisas e cursos visando ao aprimoramento de professores em exercício ${ }^{4}$. Além disso, a revista era utilizada para divulgar notas oficiais do Ministério da Educação e Saúde, transcrições de pronunciamentos nacionais e balanços a respeito da educação no país.

Com relação às representações elaboradas pelos próprios professores primários, escolhemos o exemplo de São Paulo que, no período aqui estudado, enfrentava as consequências do processo de expansão da escola pública, especificamente do ensino primário, iniciada em décadas anteriores (SPOSITO, 2002; FREITAS; BICCAS, 2009). 0 caso paulista apresenta, diferentemente do restante do país, uma considerável expansão do Ensino Normal, predominantemente na rede privada, fato que chegou a resultar, na década de 1960, em um excesso de professoras primárias no estado. Dessa forma, além do intenso debate no país acerca da necessidade de um professor especializado conforme as teorias modernas de ensino, São Paulo tinha um cenário que favoreceu a produção das representações dos professores primários, pois esses aspectos colocavam em pauta as condições e a formação para o trabalho do professor que estava em sala de aula no período.

Ao considerar a conjuntura mencionada, foram analisadas as publicações da Revista do Professor do CPP, uma das mais antigas associações de professores primários do estado, que foi fundada em 1930 com o objetivo de unir a categoria do professorado paulista. A Revista do Professor foi fundada em 1934 para divulgar ações promovidas pela diretoria do CPP, tais como as campanhas salariais que aconteceram principalmente a partir de 1958, artigos de professores filiados ao CPP e homenagens realizadas aos professores associados. Essas publicações tinham como objetivo geral propagar valores representados como comuns entre os professores primários, portanto, podemos observar em tais publicações as representações partilhadas que os professores primários tinham das

4- Dados divulgados pela RBEP do censo escolar de 1966: "de 286.895 regentes de classe, 127.879 , isto é, 44,2\% não possuem qualificação para exercer a docência." (PASQUALE, 1966, p. 236). 
dimensões emocionais de sua profissão e como o CPP - como associação representativa docente - fazia uso das emoções para representar a categoria profissional.

Essas representações não constituíam um discurso homogêneo, embora expressassem um determinado ponto de vista acerca da educação: "a feitura de um periódico apela sempre a debates e discussões, a polêmicas e conflitos; mesmo quando é fruto de uma vontade individual, a controvérsia não deixa de estar presente”. (NÓVOA apud. CATANI; BASTOS, 1997, p. 13). Sendo assim, a leitura dos periódicos precisa ser feita com objetivo de recuperar essas discussões que mostram o movimento coletivo de um grupo e suas dissidências, pois é justamente no interior delas que é possivel identificar os investimentos do grupo para perpetuar na memória o sentimento de uma identidade coletiva (POLLACK, 1992).

Ainda como forma de aprofundar a discussão acerca das representações produzidas pelos próprios professores, foram analisados romances autobiográficos de professoras que exerceram sua profissão no período estudado. Com o objetivo de retratar o período de formação e o exercício da carreira docente, localizamos duas autobiografias e um romance ficcional de professoras primárias que foram escritos no momento de suas aposentadorias.

Botyra Camorim publicou, em 1962, suas memórias, Uma vida no magistério, retratando sua carreira entre 1933 e 1952. A autora dedicou metade de suas memórias à escrita de sua experiência nas escolas isoladas do estado de São Paulo, retratando as dificuldades do exercício da docência longe do seu local de origem e denunciando a falta de apoio dos inspetores escolares.

Em Memórias de uma mestre-escola (1985), Felicidade Arroyo Nucci descreveu sua experiência no magistério entre os anos de 1933 e 1963. A autobiografia é construída por episódios de sua carreira como professora primária, enfatizando como suas práticas em sala de aula levaram ao seu aperfeiçoamento como docente. Os episódios rememorados pela autora são sempre acompanhados de reflexões acerca de práticas pedagógicas, bem como recomendações e ensinamentos às mestras inexperientes, já que Felicidade tinha a pretensão de que as "futuras mestras" fossem suas leitoras.

O arco-íris, uma carreira e a professora (1979) não é uma autobiografia, mas um romance memorialístico, em que a professora Therezinha de Jesus Penteado Monteiro usa a personagem Vera para representar as professoras de sua época. A professora descrita no romance exerce sua carreira entre 1946 e 1977. Diferentemente de Botyra Camorim e Felicidade Nucci, a personagem passa parte de sua carreira como técnica do Instituto Nacional de Estudos e Pesquisas Educacionais Anísio Teixeira Legislação e Documentos (INEP), no Rio de Janeiro.

Esses romances enriquecem a discussão proposta, na medida em que trazem representações acerca da carreira das professoras com um discurso menos prescritivo que o presente nos periódicos. Conforme Bueno (2002), a pesquisa com histórias de vida permite investigar o interior do professor e as suas experiências vividas em sua profissão.

Ao relatar suas trajetórias na carreira de professoras primárias, as autoras abarcam nas descrições representações a respeito das dimensões emocionais sobre o seu trabalho, na medida em que as emoções são utilizadas também para representar suas experiências como docentes. 


\section{Dimensões emocionais: representações em foco}

0 estudo das emoções no campo da educação é uma perspectiva de análise relativamente recente. Marchesi (2008) assinala que os estudos das emoções dos professores começam de forma tímida nos anos de 1980, com a intenção de demarcar a influência que as emoções teriam sobre o processo de ensino e aprendizagem. A partir disso, na década de 1990, começou-se a tentar compreender o trabalho dos professores, para depois analisar as emoções e como essas são afetadas pelo trabalho docente. Com base nessa perspectiva, as investigações que procuram entender o trabalho dos professores buscam aprofundar o estudo do contexto social e educacional em que elas ocorrem, como vemos em Hargreaves (1998); Estrela (2011, 2012) e Marchesi (2008).

De acordo com Damásio (2000), as emoções desempenham um papel de regulação flexível do funcionamento corporal psíquico. As emoções são, por assim dizer, um sistema dinâmico que proporciona o lidar com o desconhecido, tomadas de consciência, julgamento constante, inconsciente e consciente, das ameaças e das oportunidades do cotidiano (ESTRELA et al. 2012).

No que se refere ao trabalho histórico com o estudo das emoções, entendemos que a análise precisaria levar em conta as representações que os agentes posicionados em diferentes campos produziram, considerando os principais aspectos que influem no trabalho docente e que poderiam, de alguma forma, intervir no trabalho do professor. Portanto, foi preciso considerar as lutas de representação em que os critérios de legitimidade no campo mudam. Desse modo, pode-se perceber como os agentes com mais legitimidade impõem sua visão de mundo aos demais pertencentes ao campo:

Esta investigação sobre as representações supõe-nas como estando sempre colocadas num campo de concorrências e de competições cujos desafios se denunciam em termos de poder e de dominação. As lutas de representações têm tanta importância como as lutas econômicas para compreender os mecanismos pelos quais um grupo impõe ou tenta impor, a sua concepção do mundo social, os valores que são os seus, e o seu domínio. (CHARTIER, 1990, p. 17).

Para compreender, então, como as representações, produzidas em diferentes lugares do campo educacional, tratam das emoções no trabalho docente, portanto, tratam de um mesmo objeto, é necessário recorrer ao conceito de apropriação de Chartier (1990). Tal conceito permite-nos compreender como uma associação de professores primários, ou as professoras autoras das autobiografias estudadas, apropriaram-se dos conteúdos relativos ao conhecimento especializado educacional. Dessa forma, considerando a produção das representações sobre o trabalho docente no campo educacional como um objeto de disputa que poderia incorporar ou não as dimensões emocionais, é importante compreender as diferentes posições de cada grupo de agentes no campo. Isso porque os agentes menos legítimos, ou seja, os professores em exercício, fazem mais frequentemente referência às expressões do habitus professoral de que são portadores e que está em processo de 
modificação pelos agentes mais legítimos, representantes de uma perspectiva técnica e muito mais neutra em termos da referência à dimensão emocional.

No que se refere às dimensões emocionais, esse processo de reformas, bem como os novos e crescentes discursos acerca do aperfeiçoamento do docente em exercício influenciaram as representações sobre a profissão do magistério e as emoções dos professores primários, os quais vivenciaram esses processos de mudanças, tendo que alterar sua prática e adaptar-se às mais diversas condições de trabalho, resultantes do processo de expansão do ensino.

Esse contexto permitiu ter como hipótese que as mudanças na imagem social docente, nas condições de trabalho dos professores, na clientela atendida pelas escolas, tenham afetado fortemente os sentimentos de vinculação ao trabalho, como afirma Marchesi (2008, p. 104):

As emoções no trabalho dependem em grande medida do contexto no qual estes profissionais desenvolvem a sua atividade, das convicções sociais sobre o ensino e da regulação cultural do mundo emocional.

\section{Representações das dimensões emocionais nas fontes: alguns exemplos}

\section{Revista Brasileira de Estudos Pedagógicos}

Como já relatado, os textos coletados da RBEP mostram uma grande preocupação com a atualização pedagógica do professor. Os grandes desafios colocados nos acordos internacionais: a expansão da escola para todos e o aumento do número de brasileiros alfabetizados transformavam-se em novas competências para os docentes em exercício. Era necessário que o professor conseguisse compor em sua prática as necessidades de aprendizagem na diversidade cultural e emocional de seus alunos. 0 artigo Aplicações da educação: origem dos sentimentos de insegurança e angústia (1951), da professora Lúcia Marques Pinheiro, que fazia parte da direção do INEP, exemplifica a preocupação em ter um docente com essas competências:

As experiências intelectuais e emocionais da criança não oferecem nada de semelhante, e, a menos que haja adultos em que ela tenha carinho e compreensão, que possam constituir para ela um ponto de apoio afetivo, a criança será presa de um sentimento de total indefesa. [...]. Como lição prática, final, para nós, educadores, parece-nos que deve calar fundo a importância que apresentam, para o desenvolvimento emocional da personalidade. (PINHEIRO, 1951, p. 74).

0 trabalho do professor, conforme o artigo, ganha um estatuto mais profundo, pois afeta a personalidade do educando, podendo realizar uma prática de prevenção de traumas emocionais futuros (sentimento de insegurança e angústia), através de uma relação emocional baseada em carinho e compreensão. Essa linha argumentativa pode ser percebida em outros artigos, de modo que a representação das emoções, nesses casos, 
foi frequentemente associada à personalidade e atitudes que o professor poderia ter para influenciar positivamente ou negativamente a saúde emocional do aluno. Como vemos no artigo de Riva Bauzer, técnica do INEP, são destacadas as influências que os professores primários podem ter sobre a saúde mental do aluno:

Quem diz saúde mental diz utilização inteligente do capital emocional de que cada um de nós dispõe [...] os professores precisam dar muita atenção à saúde de seus alunos; por outro lado podem exercer uma grande influência sobre a saúde de seus alunos [...]. Além disso, as próprias atitudes equilibradas do professor afetam os sentimentos de bem-estar dos alunos, aumentando o seu interesse pela escola e pelos trabalhos de classe. (BAUZER, 1956, p. 135).

0 professor, nesses casos, além de influenciar a saúde mental do aluno com a sua percepção sobre as suas emoções, pode também educá-lo por meio de suas atitudes equilibradas. Ainda na temática da preocupação da relação emocional entre o professor e o aluno, encontramos argumentos que descrevem a necessidade de selecionar o professor primário antes e após a formação inicial. Para isso, seriam necessários testes vocacionais com base em teorias da psicologia e psicotécnica para selecionar a personalidade mais adequada ao exercício do magistério. A seleção antes do curso do magistério era, dessa maneira, uma forma de prevenir a frustração com a carreira. Em um texto escrito pela professora Riva Bauzer, do Rio de Janeiro, descrevem-se as qualidades que deveriam ser averiguadas na seleção de candidatos ao curso Normal:

0 bom professor, o verdadeiro educador, é aquele que consegue estabelecer e manter relações
harmoniosas com seus alunos, caracterizadas por simpatia e compreensão. [...]. No outro lado da
escala encontramos o professor que procura dominar a classe de qualquer maneira. Conseguindo
esse intento passa a reger a sua turma com punho de ferro, criando simultaneamente uma atmosfera
de grande tensão emocional, de medo, de submissão. Quando, porém, apesar de seus esforços,
não consegue dominar a classe passa a exibir comportamento de nervosismo, temor, desespero,
que projeta sobre sua turma, contribuindo para o aparecimento de frustrações, inquietações,
desatenção, vadiagem, atitudes acintosas de desrespeito, etc., que exigem constantes soluções de
cunho disciplinar rígidas e inflexíveis. [...] podemos dizer que as atitudes do professor, derivadas
de seu equilíbrio emocional e dos fatores acima citados, são a chave que nos permite prever o
tipo de atuação que o professor vai exercer dentro da sala de aula. (BAUZER, 1954, p. 221-223).

Novamente, o relacionamento emocional entre professores e educandos é colocado não somente como necessário a uma prática de sucesso, mas também como definição de um bom professor. Depende do conhecimento pedagógico e da personalidade do professor controlar o ambiente emocional da sala de aula, o que estabelecerá o sucesso na relação de ensino e aprendizagem. No entanto, para que o professor mantivesse essa personalidade e o conhecimento necessário para uma prática pedagógica de sucesso era necessário que se aperfeiçoasse constantemente, como forma de valorizar a sua própria profissão.

Lourenço Filho, em um longo discurso que foi proferido em ocasião da aula inaugural dos Cursos de Aperfeiçoamento e Especialização no Instituto de Educação do Rio de Janeiro, descreveu vários estudos realizados acerca da personalidade do professor na França e na 
Suiça, e concluiu que a combinação de personalidade própria do professorado, que "sabe demonstrar o que quer”, mais o constante aperfeiçoamento, que garantiria a utilização "dos modernos procedimentos de ensino", seria a chave para uma boa docência:

0 bom professor deve demonstrar que sabe o que quer e como quer, muito embora não deva usar de procedimentos coercitivos, como se fazia na escola tradicional. Certamente o conhecimento e o domínio dos modernos procedimentos de ensino com boa motivação, constituem fator importante. Mas não dominam tudo, se não estiverem afeiçoados à personalidade do docente, dela fluindo a expressão natural. Uma professorinha tímida e insegura pode ser muito interessante para figurar numa novela ou num filme romântico. Mas, na escola, absolutamente não. 0 mestre deve saber o que quer, pois só assim poderá saber também como deverá querer. [...] (LOURENÇO FILHO, 1954, p. 54).

Além das representações do bom professor e das qualidades que lhe são necessárias, encontramos também representações do que seria o professor emocionalmente desajustado para a sua função. No período, era comum que os professores iniciassem a carreira em lugares distantes de sua origem e com condições de trabalho, muitas vezes, precárias. 0 argumento era o de que as condições de trabalho, combinadas com uma personalidade e formação inadequadas ao magistério, acabavam por deixar o professor emocionalmente desajustado.

No artigo Exame psicológico de candidatas ao magistério de Maceió, Paulo Rosas (1967) assinala a insuficiência das provas escritas para a seleção de professores, pois esse método não garantiria a seleção de professoras "equilibradas emocionalmente", tampouco verificaria se tinham vocação para o magistério. 0 autor caracteriza a boa professora primária da seguinte forma:

Para ser possível o êxito social, deve a professora primária, cumprir contatos sociais com espontaneidade e satisfação. Compete-lhe, pois, viver o valor social, e não apenas simplesmente sofrê-lo. Além disso, esse gosto pelo social, que é indispensável a qualquer nível do ensino primário, deve ser corporificado ao amor à criança, na satisfação de trabalhar com as crianças, de responder esportivamente a seus desafios [...] (ROSAS, 1967, p. 121).

Nesse estudo, realizado em Maceió, foram aplicados vários testes nas professoras candidatas. Os testes, com base na psicologia e psicometria do trabalho, objetivaram medir os graus de inteligência das professoras no que se referia ao traço emocional e ao raciocínio. Foi constatado que muitas dessas professoras sofriam um desajustamento emocional em relação à profissão por trabalharem em lugares distantes do local de origem, por não terem capacidades relacionadas à inteligência de raciocínio e emocional e ainda, em alguns casos, por sofrerem com maridos que tinham escolaridade de menor duração e que, segundo o autor, por esse fato controlavam as possibilidades de suas esposas dentro da profissão docente.

Foi possivel observar nos artigos da RBEP que as dimensões emocionais são representadas em meio aos argumentos acerca do aperfeiçoamento e a seleção do 
professor primário. Dentro dessa temática, as emoções no trabalho docente constituem um elemento integrado à dimensão técnica, pois era preciso selecionar o professor com um perfil emocional adequado à prática pedagógica e ainda formá-lo de maneira que fosse possível um bom relacionamento emocional com os alunos. De outra forma, "desajustes emocionais" poderiam ocorrer, fato que, segundo os artigos, não corresponderia a uma prática de ensino moderna.

\title{
Revista do Professor do CPP
}

A prática pedagógica foi amplamente representada pelos artigos do CPP: em forma de recomendações, análises dos novos e modernos métodos de ensino e até mesmo por meio das descrições realizadas nas homenagens aos velhos mestres, de modo que essas representações acerca das práticas estavam na maioria das vezes interligadas com as representações sobre as dimensões emocionais. No artigo de Oscar Augusto Guelli, são descritas as características ideais para um ambiente escolar que proporcione alegria às crianças:

\begin{abstract}
[...] alegre e sugestivo há de ser o ambiente escolar se queremos que nele vicejem as mais lindas flores da nossa inteligência [...]. E a escola nunca deve deixar de ser uma benção, uma esperança, uma afeição, porque a criança é a flor que perfuma e santifica a existência, como símbolo mais perfeito que é da Beleza e do Amor. A escola é precioso jardim de corações e o jardineiro há de estar à altura dessa nobreza que se lhe confia. A cultura de corações, muito mais delicada do que a de inteligência, exige qualidades de verdadeira abnegação, de grande elevação moral. Quem não tiver o hábito das belezas morais e familiares com as dedicações; quem não souber querer amar, revelar e perdoar, rir e afagar; quem não tiver a boa fortuna de se identificar com o destino de seus educandos, nunca será professor de fato, por maior competência que tenha e por mais vigorosa que seja sua inteligência. (GUELLI, 1954, p. 4).
\end{abstract}

São listadas não somente as representações de emoções relacionadas à prática de ensino, mas também representações que definem o que seria o bom professor: abnegação e amor. A presença das emoções na prática pedagógica não é apenas justificada como uma forma de estabelecer um vínculo entre o professor e o aluno para o aprimoramento do processo de ensino, mas também como uma finalidade em si. 0 exemplo do professor primário deveria indicar o amor como prática.

É interessante notar no texto a preocupação com um perfil emocional do professor, que também encontramos nos artigos da RBEP. No entanto, a estrutura do discurso apresentada pelos professores do CPP tem uma grande diferença. Sem referências ao que seria uma educação moderna ou aos padrões de prática colocados pela cientificidade educacional, o artigo descreve livremente qualidades morais e emocionais tidas como necessárias ao bom professor. Os artigos da Revista do Professor, ao contrário do encontrado na RBEP, buscavam argumentar acerca da prática dos professores com base na própria experiência que os autores tinham com o cotidiano escolar ou, nos termos de Tardif (2000), nos saberes da experiência do trabalho docente, ou seja, um saber constituído na história de vida do professor (pessoal e profissional). 
Entretanto, apesar de fazer, frequentemente, menos referência à necessidade de modernizar a prática e a formação docente, essa temática também aparece nos artigos encontrados na revista do CPP, o que pode ser considerado exemplar a respeito de como o discurso sobre a cientificidade educacional aplicada à prática estava sendo apropriada pelos professores. Ou seja, apesar de fazer referências ao que seria baseado na moderna pedagogia, os exemplos relatados baseiam-se na experiência do autor com a prática, como é o caso do artigo Professoras feias, de Mateus L. de Abreu. No texto são descritos os professores do Brasil Império, homens que "da ciência pedagógica só conheciam o obsoleto lema romano - 'a letra com sangue entra' [...] meio altos, meio corcundas, meio calvos, magricelas [...] símbolos de escola infernal" (ABREU, 1957, p. 12). Para o autor, a feminização do magistério trouxe vantagens para o ensino, pois as mulheres têm: "instinto da maternidade, que são mais pacientes, mais bondosas, meigas, que têm mais pendores para a tarefa de educar crianças”. Todavia, o autor identifica algumas exceções entre estas mulheres:

Algumas professoras desajeitadas dão de ombro às sábias lições da pedagogia científica e preconizam sua falência. Revestem-se de autoridade masculina, draconiana, forçam o silêncio das classes em altas vozes, xingamentos repetidos, beliscões e até bofetões [...]. De tanto carregar o cenho, adquirem a carranca permanente, olhos vidrados, mãos esquálidas, tudo quanto torna feia a mulher. Ora, a mulher moça ou idosa, casada ou solteira, professora ou não, sempre deseja ser bonita, atraente. 0 fato nos levava, nas saudosas aulas de pedagogia, a alertar as professorandas no sentido de que permanecessem boas, meigas, pacientes, para que não ficassem professoras feias... (ABREU, 1957, p. 12).

Vemos no relato a transição que ocorre com o processo de feminização do magistério, ou seja, a passagem da imagem de um professor: homem, sério, alheio às teorias, mas que pela experiência do ensino (pelo "sofrimento") cumpria o seu papel. Em oposição, temos a representação da professora mulher: dócil, maternal, que tem naturalmente a habilidade de se relacionar emocionalmente, de forma positiva, com os seus alunos.

A descrição do afeto pelos alunos e o amor pela docência eram colocados nos artigos dessa revista não só como característica necessária à docência, como também necessária para a representação desses professores como categoria profissional. 0 dia do professor, como ritual de celebração, é marcante no que se refere à construção das representações sobre o professor primário pela categoria, pois os textos descrevem qualidades tidas como adequadas ao docente, colocando em evidência valores, práticas e emoções valorizadas pelo grupo:

As frases bonitas comparando a sua função ao sacerdócio. Começam a ter tom de ironia a seus ouvidos. Não é que você tenha perdido o gosto pelo magistério. [...]. 0 seu devotamento, o novo estímulo que conseguiu é algo de consciente. Você já teve contato com a realidade, já sentiu a rudeza, ali mesmo, onde antes imaginara encontrar um mundo fácil e encantado. [...]. Esses atributos, você os adquire de forma milagrosa, incompreensível aos olhos materialistas da sociedade hoje. É o milagre do AMOR. Do amor que você sente pelo seu aluno e que a leva a querer resguardá-lo das tristezas de uma vida adversa. É o amor à obra de redenção que você se 
propõe realizar, por muito que custe. É a esse professor que queremos falar. A esse professor que, dentro da sala de aula, se transforma. Já não se lembra de suas próprias dificuldades, esquece-se dos aborrecimentos seus, de sua família; esquece-se dos desgostos lá de fora, para transformarse ante os olhos do aluno, no anjo feliz e protetor. [...]. Siga assim, PROFESSOR. Ame a criança; procure dar-lhe a diretriz segura de honestidade e de nobreza de caráter, que o homem perdeu. (REVISTA DO CPP, 1954, p. 11-12).

A representação da profissão do professor é colocada como um sacerdócio, com uma missão quase divina de recuperar um passado representado como glorioso, comparado a um presente com valores em declínio. É interessante observar que o elemento colocado como crucial para o bom andamento da carreira, ou seja, o fator que fará com que o professor primário supere as dificuldades mencionadas, como a vida na escola rural, as decepções do trabalho nos grupos escolares, é justamente o amor encontrado no devotamento à profissão. Esse amor pela docência é definido pelo ato de desconsiderar as dificuldades e dedicar-se ao ensino como se elas não existissem, com a motivação marcada pela importância de seu trabalho em serviço dos alunos. As emoções na docência são representadas então como uma forma de caracterizar e justificar o sacerdócio e a nobreza da profissão, as quais estariam acima de qualquer dificuldade.

Outro aspecto a ser considerado é o fato desse texto ter sido publicado em ocasião do dia do professor, data que, como identificam Vicentini e Lugli (2009), é uma fonte de recompensa simbólica da profissão, ou seja, o reconhecimento externo pelos feitos na carreira, com homenagens, prêmios etc. Podemos encontrar na revista uma diversidade de textos por ocasião do dia do professor, visto que o CPP, como associação do magistério primário paulista, promovia diversas festividades para celebrar a data. 0 que se pode observar é que as emoções no trabalho docente eram utilizadas em praticamente todos os casos, como forma de representar o amor que o professor primário tem pelo aluno e o seu vínculo sacerdotal com a profissão.

As representações das dimensões emocionais na Revista do Professor evidenciam, de modo geral, o uso das emoções como forma de representar um coletivo, no caso uma categoria profissional. Como no exemplo colocado acima, vemos a tentativa de descrever um professor primário que representasse a categoria e, para isso, as emoções constituem um elemento central na construção dessa representação.

\section{Romances memorialísticos}

As autobiografias estudadas descrevem com detalhes a rotina e a prática em sala de aula, fazendo comparações com o que foi aprendido na Escola Normal. Botyra Camorim enfrentou várias dificuldades (relativas tanto ao choque entre teoria e prática como à condição de trabalho) no início do magistério, chegando até mesmo a desistir. Mesmo quando voltou a trabalhar como professora, Camorim ainda passou por experiências difíceis, achando a própria aula monótona. Para essa professora, o conhecimento obtido em sua formação não fazia sentido na realidade das primeiras escolas em que exerceu o magistério, as quais eram escolas isoladas. 
Essas escolas, localizadas no interior do estado de São Paulo, ou em locais considerados afastados, muitas vezes não tinham um lugar específico, funcionavam em locais cedidos pela comunidade local (muitas vezes por pessoas influentes na região) ou então em locais alugados pelos próprios docentes. Pelas dificuldades encontradas na relação entre os conhecimentos especializados e a realidade encontrada nas escolas, os professores que escreveram suas memórias remetem à percepção de que na experiência é que se encontra de fato um saber para o exercício do magistério.

É possível perceber, por meio dos relatos das professoras, que elas construíram um saber através da prática, das aulas que não tiveram sucesso, do contato com as comunidades, com as famílias, com cada tipo de escola (escolas isoladas, grupos escolares, escolas reunidas etc.). A esse respeito, Tardif, Lessard e Lahaye (1991) analisam os tipos de saberes que podem ser encontrados no exercício docente e dentre eles dão destaque para os saberes da experiência, isto é, saberes adquiridos durante o exercício profissional, no cotidiano, enfım, de sua experiência: "Esses saberes brotam da experiência e são por ela validados. Eles incorporam-se à experiência individual e coletiva sob forma de habitus e de habilidades, de saber-fazer e de saber-ser." (TARDIF; LESSARD; LAHAYE, 1991, p. 39).

Para esses autores, o saber docente está relacionado com a constituição da identidade da professora, considerando sua trajetória profissional e de vida, ou seja, é um saber construído por meio das relações sociais. Esses saberes da experiência aparecem fortemente nos relatos memorialísticos das professoras, como podemos observar no desejo de Felicidade de deixar as suas memórias para que as futuras mestras aprendam com a sua experiência: "É porque esse tempo deixou saudades é que desejo transmitir àquelas que iniciam a difícil jornada de mestras da infância, as minhas experiências adquiridas à custa de muitos tropeços" (NUCCI, 1985, p.69). Do mesmo modo, podemos ver nas considerações de Botyra Camorim acerca do que aprendeu no convívio, observação e relação emocional com os educandos:

[...] nestes vinte e sete anos de magistério, convivi com crianças de todas as raças e classes sociais. Entre elas pude observar que o seu mundo é idêntico ao do adulto. Existem as mesmas misérias, humilhações, orgulho, bondade, desprendimento, amor, alegrias e tristezas. [...]. Observando e estudando o caráter de cada uma acompanhando sua evolução, era com imensa alegria que me via triunfar fazendo brotar, nas almas pequeninas, as flores da bondade e candura que todas possuem no coração. (CAMORIM, 1962, p. 19).

Botyra registra o primeiro momento em que ela começa, em suas palavras "a ter fé" nela mesma, a partir de elogios feitos por um inspetor escolar: "0 inspetor escolar veio para fazer os exames e eu tive uma aprovação de oitenta por cento que na opinião dele, foi ótima, uma das melhores da região. Comecei então, a ter fé em mim própria." (CAMORIM, 1962, p. 69).

Monteiro (1979) relata como sua personagem ficou emocionada com o prêmio de alfabetização obtido logo no início de sua carreira, quando ainda era substituta: 
Terminou seu discurso com a frase por todos conhecida: 'Creio na educação e por que nela creio, trabalho e luto'. Vera não sabe se o momento repassado de suave e profunda emoção [...] Empenhou-se de corpo e alma nessa campanha. [...]. Esse foi um caso entre os aproximados 50\% de alfabetizações alcançadas. 0 método foi o ensino individual. A satisfação por esse empreendimento foi grande. Dele ficou uma recordação distante no tempo e sempre próxima no contentamento nunca apagado. (MONTEIRO, 1979, p. 20).

Além da recompensa simbólica, exemplificada no texto acima em que a professora Vera ganha um prêmio pelo número de alunos alfabetizados, temos nas autobiografias relatos que mostram a satisfação das professoras primárias em constatar a aprendizagem dos alunos: "meu trabalho começou a aparecer. As crianças aprendiam depressa [...]. Trabalhava satisfeita vendo o resultado do meu trabalho". (CAMORIM, 1962, p. 76).

Esse é um exemplo do que Hargreaves (1998) identifica como recompensa psíquica no trabalho docente, ou seja, por ser o processo de aprendizagem o principal, e mais cobrado, objetivo do trabalho docente, a satisfação em alcançá-lo é um fator positivo para o bem-estar emocional dos professores no trabalho em sala de aula. Diferente da recompensa simbólica, mencionada anteriormente, que remete a um reconhecimento externo (como através de prêmios, reconhecimento de outros agentes da escola ou de homenagens), a recompensa psíquica é fruto da interação da professora e do aluno, ou seja, interna à relação.

Um fato recorrente nas narrativas dessas professoras é que, apesar das dificuldades enfrentadas, elas afirmam por diversas vezes a importância de ser professora (seja na relação da profissão com uma missão divina ou como uma missão para a transformação da sociedade) e a realização que alcançaram com a profissão:

A escola foi o refúgio tranquilo do meu coração [...]. Tempestades d'alma, luto, ingratidões e desenganos, chocavam-se e desfaziam ante a algazarra e alegria infantis. A minha assiduidade, sempre teve um pouco de egoísmo da minha parte. No período mais tormentoso de minha vida, trabalhei durante três anos sem dar faltas. (CAMORIM, 1962, p. 17).

Assim sendo, podemos fazer relação com o conceito de illusio, de Pierre Bourdieu. Illusio é "estar preso ao jogo[,] é acreditar que o jogo vale a pena, para dizê-lo de maneira mais simples, que vale a pena jogar" (BOURDIEU, 1996, p. 139). Dessa maneira, uma pessoa pertencente a um campo pode estar tão submersa no modo e forma de funcionamento que os preceitos e ideais dessa atividade em particular (capital específico) são incondicionalmente importantes:

É 'estar em', participar admitir, portanto, que o jogo merece ser jogado e que os alvos engendrados no e pelo fato de jogar merecem ser perseguidos; é reconhecer o jogo e reconhecer os alvos. (BOURDIEU, 1996, p. 139-140).

Podemos usar o conceito de illusio, então, para discutir a forma pela qual as professoras, apesar de todas as adversidades do cotidiano, permanecem ligadas à profissão: 
Pela primeira vez o governo do Estado homenageou professoras primárias, por mais de noventa por cento de alfabetização. Na lista publicada no Diário Oficial, meu nome também figurou. [...]. Ao sentir em minhas mãos a fria medalha, apertei-a com força e por um momento. Lembrei do meu primeiro ano escola, terrível para mim, tendo a minha volta dúvidas e fracassos. Não fora a Imutável Força do Céu, não teria eu, naquela tarde de agosto, recebido a porcentagem de alfabetização do ano do quarto centenário da minha terra, mas sim, os anos todos de uma luta ingrata nessa ingrata carreira que é o magistério, mas que para mim representa uma vida bem vivida. (CAMORIM, 1962, p. 18).

Essas representações acerca das dimensões emocionais, que argumentamos serem parte do habitus professoral, também têm relação com a illusio do campo educacional, ou seja, as emoções parecem constituir não só parte da docência como trabalho de interação, como são também parte dos modos de organização do campo educacional. Ou seja, as representações mostram que quanto mais socializado no campo, mais fortes essas emoções pareciam atuar em relação à carreira dessas professoras.

\section{Principais conclusões}

Pode-se verificar, a partir das discussões trazidas das fontes como exemplo, as diferenças das representações das dimensões emocionais correspondentes aos lugares diferentes do campo educacional em que cada fonte tem origem: a RBEP e a produção do conhecimento científico sobre educação, a Revista do Professor do CPP como associações de professores e os romances memorialísticos como registro dessas representações produzidas individualmente pelas próprias professoras primárias. A estrutura dessas diferenças é concernente à forma como a profissionalização dos professores estava ocorrendo no período: o discurso cada vez mais especializado, representado aqui pela RBEP, fonte da cobrança de atualização pedagógica com base em conhecimentos científicos por parte do professor primário e, por outro lado, pelos professores primários que, apesar de se apropriarem da noção da importância da modernização do ensino, continuavam a atribuir grande importância à prática aperfeiçoada por meio da experiência e ao relacionamento emocional com o trabalho. As emoções passaram a fazer parte de uma disputa para determinar o que constitui a boa prática.

$\mathrm{Na}$ RBEP, as dimensões emocionais integravam-se, a partir da psicologia, a mecanismos de seleção e controle do trabalho. Para o CPP, tratava-se da recompensa simbólica da profissão. Para ambos os polos dessa disputa, a definição do bom professor estava marcada por sua capacidade de regular o aspecto emocional das interações em sala de aula. A questão relativa aos vencedores nesse embate não é de resposta simples: no plano das representações, assistiu-se, durante o século XX, a um apagamento dos valores e do modo de conceber o magistério tal como aparecia nas produções do CPP pode-se imaginar que em parte isso se deveu à mudança política na representação dos professores, que passou a apresentá-los como "trabalhadores do ensino", em conflito com 
o "Estado-patrão", particularmente a partir de $1979 .{ }^{5}$ Também não se viram iniciativas de longa duração para a seleção de professores com base no "ajustamento emocional" e, mesmo hoje, não se veem iniciativas para preservar os docentes dos desgastes emocionais do trabalho - embora haja um discurso muito disseminado acerca do impacto deletério da situação do ensino sobre a condição psíquica dos docentes. Nesse sentido, podemos falar em um apagamento das emoções nas representações acerca da docência ${ }^{6}$.

Também se pode assinalar que há uma dimensão do tratamento das emoções que permaneceu bastante fiel aos valores mais tradicionais, de modo mais ou menos subterrâneo, justamente porque ligada às práticas. As memórias das professoras primárias expressam essa permanência das emoções fortemente ligadas ao modo de trabalho e às suas recompensas psicológicas e simbólicas. Como agentes menos legítimas da amostra considerada do campo educacional no período, suas opiniões dificilmente têm consequências acerca da natureza das representações correntes ou consequências práticas de maior alcance na organização dos sistemas de ensino.

\section{Referências}

ABREU, Mateus. Professoras feias. Revista do Professor, São Paulo, v. 15, n. 34, p. 12, set. 1957.

BAUZER, Riva. Caminhos que levam a aprendizagem. Revista Brasileira de Estudos Pedagógicos, Brasília, DF, v. 25, n. 61, p. 132, jan./mar. 1956.

BAUZER, Riva. Personalidade do professor primário. Revista Brasileira de Estudos Pedagógicos, Brasília, DF, v. 22, n. 56, p. 221-223, nov./dez. 1954.

BOURDIEU, Pierre. Coisas Ditas. São Paulo: Companhia das Letras, 1990.

BOURDIEU, Pierre. Lições da aula. São Paulo: Ática, 2001.

BOURDIEU, Pierre. Os usos sociais da ciência: por uma sociologia clínica do campo científico. São Paulo: Edunesp, 2004.

BOURDIEU, Pierre. Razões práticas: sobre a teoria da ação. Campinas: Papirus, 1996.

BUENO, Belmira Oliveira. 0 método autobiográfico e os estudos com histórias de vida de professores: a questão da subjetividade. Educação e Pesquisa, São Paulo, v. 28, n. 1, p. 11-30, jan. /Jun. 2002.

CAMORIM, Botyra. Uma vida no magistério. São Paulo: Saraiva, 1962.

\footnotetext{
5- A partir da greve de professores de 1979, e como fruto de uma mudança no perfil de formação e de contratação dos docentes do ensino público em São Paulo, as representações da docência vinculadas ao CPP como associação representante dos professores primários perderam a predominância, passando a ocupar o primeiro plano uma perspectiva mais sindical, que fazia equivaler os professores a trabalhadores e 0 Estado ao "patrão". Desse modo, um conjunto de imagens que mesclava elementos do sacerdócio com a imagem do funcionário público dedicado ao bem comum passou a ser percebida como "desatualizada" e "despolitizada". Ver Vicentini (2005) e Lugli (1997).

6- Ver mais detalhes em Costa (2016).
} 
CATANI, Denice Barbara; BASTOS, Maria Helena Camara (Org.). Educação em Revista: a imprensa periódica e a história da educação. São Paulo: Escrituras, 1997.

CPP. Centro do Professorado Paulista. Professor! Oração proferida no CPP em XV de outubro de 1953, comemorando o Dia do Professor. Revista do Professor, São Paulo, v. 12, n. 19, p. 11-12, fev. 1954.

CHARTIER, Roger. A história cultural: entre práticas e representações. Rio de Janeiro, Difel, 1990.

COSTA, Marina Mendes da. Ser e sentir-se docente: representações das dimensões emocionais do trabalho docente em periódicos educacionais e romances memorialísticos de professoras primárias (1950-1970). 2016. 171p. Dissertação (Mestrado em Ciências da Educação e da Saúde) - Escola de Filosofia, Letras e Ciências Humanas, Universidade Federal de São Paulo, Guarulhos, 2016.

DAMÁSIO, António. 0 mistério da consciência: do corpo e das emoções ao conhecimento de si. São Paulo: Companhia das Letras, 2000.

ESTRELA, Maria Teresa. A dimensão emocional da docência: contributo para a formação de professores. Revista Portuguesa de Pedagogia, Lisboa, v. 46-2, p. 151-171, 2012.

ESTRELA, Maria Tereza et al. Trabalho docente, emoções, contextos e formação. In: SIMPOSIUM NACIONAL SOBRE FORMAÇÃO E DESENVOLVIMENTO ORGANIZACIONAL, 2., 2011, Lisboa. Anais... Lisboa: ISCTE, 2011. p. 40-53. Disponível em: <https://repositorio.ul.pt/bitstream/10451/8665/1/Trabalho_docente_ Freire_Bahia_Estrela_Amaral.pdf >.Acesso em 03 de dez. 2018.

FERREIRA, Márcia Santos. Os centros de pesquisas educacionais do INEP e os estudos em ciências sociais sobre a educação no Brasil. Revista Brasileira de Educação, Rio de Janeiro, v. 13 n. 38, p. 279-291, maio/ ago. 2008.

FREITAS, Marcos Cezar de; BICCAS, Maurilane de Souza. História social da educação no Brasil (1926-1996). São Paulo: Cortez, 2009.

GANDINI, Rachel Pereira C. Revista Brasileira de Estudos Pedagógicos (1944-1952): intelectuais, educação e estado. 1990. 249f. Tese (Doutorado em Educação) - Faculdade de Educação da Universidade Estadual de Campinas, Campinas, 1990.

GUELLI, Oscar A. 0 ensino nas escolas rurais. Revista do Professor, São Paulo, v. 7, n. 5, p. 29, ago.1950. Segunda fase.

HARGREAVES, A. The emotional practice of teaching. Teaching and Teacher Education, New York, v. 14, p. 835-854, 1998.

LOURENÇO FILHO. Aperfeiçoamento do magistério primário. Revista Brasileira de Estudos Pedagógicos, Brasília, DF, v. 23, n. 78, p. 39-54, abr./jun. 1960. 
LUGLI, Rosario Silvana Genta. Um estudo sobre o CPP (Centro do Professorado Paulista) e o movimento de organização dos professores (1964-1990). 1997. 307 f. Dissertação (Mestrado em Educação) - Faculdade de Educação da Universidade de São Paulo, São Paulo, 1997.

MARCHESI, Álvaro. 0 bem-estar dos professores: competências, emoções e valores. Tradução de Naila Tosca de Freitas. Porto Alegre, Artmed, 2008.

MONTEIRO, Teresinha de Jesus Penteado. 0 arco-íris, uma carreira e a professora. São Paulo: Franciscana, 1979.

NUCCI, Felicidade Arroyo. Memórias de uma mestre-escola. São Paulo: Edição do Autor, 1985.

PASQUALE, Carlos. Desenvolvimento do ensino primário e o Plano Nacional de Educação. Revista Brasileira de Estudos Pedagógicos, Brasília, DF, v. 45, n. 102, p. 236-256, abr./jun. 1966.

PINHEIRO, Lúcia Marques. Inquérito sobre a formação do professor primário. Revista Brasileira de Estudos Pedagógicos, Brasília, DF, v. 38, n. 87, p. 107-136, jul./set. 1962.

POLLAK, Michael. Memória e identidade social. Estudos Históricos, Rio de Janeiro, v. 5, n. 10, p. 200-212, 1992.

ROSAS, Paulo. Exame psicológico de candidatas ao magistério primário. Revista Brasileira de Estudos Pedagógicos, Brasília, DF, v. 30, n. 71, p. 125-136, jul./set. 1967.

SPOSITO, Marília Pontes. 0 povo vai à escola: a luta popular pela expansão do ensino público em São Paulo. São Paulo: Loyola, 2002.

TARDIF, Maurice. Saberes docentes e formação profissional. 2. ed. Petrópolis: Vozes, 2002.

TARDIF, Maurice. Saberes profissionais dos professores e conhecimentos universitários: elementos para uma epistemologia da prática profissional dos professores e suas consequências em relação à formação para o magistério. Revista Brasileira de Educação, Rio de Janeiro, n. 13, p. 5-24, jan./abr. 2000.

TARDIF, Maurice; LESSARD, Claude. Esboço de uma problemática do saber docente. Teoria \& Educação, Porto Alegre, v. 1, n. 4, p. 215-233, 1991.

TARDIF, Maurice; LESSARD, Claude. 0 trabalho docente: elementos para uma teoria da docência como profissão de interações humanas. 7. ed. Tradução: João Batista Kreuch. Petrópolis: Vozes, 2002.

VICENTINI, Paula Perin. A profissão docente no Brasil do século XX: sindicalização e movimentos. In: BASTOS, Maria Helena Câmara; STHEFANOU, Maria (Org.). Histórias e memórias da educação no Brasil século XX. Petrópolis: Vozes, 2005. p. 336-346.

VICENTINI, Paula Perin; LUGLI, Rosario S. Genta. História da profissão docente no Brasil: representações em disputa. São Paulo: Cortez, 2009. 
Recebido em: 29.11.2018

Aprovado em: 26.02.2019

Marina Mendes da Costa é pedagoga pela Universidade Federal de São Paulo (UNIFESP), mestre em ciências pelo Programa de Pós-Graduação em Educação e Saúde na Infância e na Adolescência da UNIFESP e doutoranda em educação pela Faculdade de Educação da Universidade de São Paulo (FE/USP).

Rosario Silvana Genta Lugli é pedagoga pela Faculdade de Educação da Universidade de São Paulo (FE/USP), por onde também é mestre e doutora em educação. É professora do Departamento de Educação da Universidade Federal de São Paulo (UNIFESP). 